\title{
Review of Recycling and Processing of Waste Electronic Equipment
}

\author{
Danyang $\mathrm{Li}^{1}$ \\ ${ }^{1}$ School of Environmental Science and Engineering Department, North China Electric Power \\ University, Baoding 071003, China;
}

a522458896@qq.com

Keyword: Waste; Electrical equipment; The environmental pollution; Recycling.

\begin{abstract}
With the increase of the use of electrical and electronic products in our country, electrical products renewal speed, the life cycle of the electric and electrical products reduce greatly. Waste electronic equipment increased year by year. Over the past five years, the United States and a few European countries export a lot of waste electrical equipment exported to coastal areas in China. This makes the problem worse. China has become the world's second largest electronic waste produce countries, after the United States. Waste electronic equipment contains many toxic and harmful substances. If we are not handled properly, it will endanger health of human body and cause great pollution to the environment [1]. The waste electronic equipment contains many recyclable things. Our science recycling of waste electronic equipment has good economic and social benefits. In this paper, we investigate and analysis based on processing status of China and abroad on waste electronic equipment. Then, we give waste electronic equipment processing and recycling instructional Suggestions in the future.
\end{abstract}

\section{Introduction}

With the rapid development of electronic information industry, the speed of electronics and hi-tech products renewal becomes faster and faster. Corresponding, the electronic product life cycle is becoming more and more short, the number of electrical waste increased sharply. The European Union published a report on electronic waste. The report points out that the electronic waste is growing at $16 \% \sim 28 \%$ in five years. It is three times faster than the growth rate of total solid waste. Nowadays, electronic waste is the fastest growing part of the city garbage. As a big electronic products production and consumption country, Chinese electrical waste recycling and disposal problem has been not effectively resolved.

\section{Research Background}

Potential Environmental Polluting. Electronic waste is also known as e-waste, including all kinds of waste televisions, refrigerators, air conditioners, washing machines, computers, communications equipment, and elimination of precision electronic instruments and meters, etc. The waste electrical equipment have potential environmental polluting. Improper handling can cause pollution to the environment. The waste electrical equipment contains a lot of poisonous and harmful substances [2]. If you savage and dismantling, optional landfill or burned directly after abandoned, it will cause serious pollution of air, soil and water. The operators and threatens the lives of the residents.

This will threaten operators and the lives of the residents. Such as refrigerator, air conditioner refrigerant, heat preservation and heat insulation materials contain CFCS. On the one hand, it will 
consume ozone in the atmosphere, on the other hand, it will exacerbate the greenhouse effect. It will cause great harm to ecological environment if it is discharged directly. And such as computer, TV kinescope glass contains a lot of lead (exist in the form of $\mathrm{PbO}$ ). If discarded after broken, it will seriously pollute the groundwater and soil, threat to residents' health and safety of drinking water.

Regenerative Potential Resources. Waste electronic equipment has potential resources renewable. If we can adopt advanced industrial technology for processing, most of the original and the high content of precious metals will be raw materials of industrial products and electronic products. On the one hand, it will greatly alleviate the shortage of energy resources sharp contradictions, on the other hand, it also will certainly to obtain good economic benefits. At the same time, it solve the problem of waste produced by environmental hazards, it can obtain the better social environment benefit. The waste equipment contains plenty of renewable resources. Such as all kinds of non-ferrous metals, ferrous metals, plastics, glass and some are still valuable parts, etc. it went by the name of "urban mining" which is equally important to the natural mineral resources. According to statistics, one ton of random computer board contain $272 \mathrm{~kg}$ plastic, $130 \mathrm{~kg}$ of copper, $0.45 \mathrm{~kg}$ of gold, $41 \mathrm{~kg}$ iron, $29 \mathrm{~kg}$ lead $18 \mathrm{~kg}, 20 \mathrm{~kg}$ tin, nickel, antimony $10 \mathrm{~kg}, 9 \mathrm{~kg}$ silver and palladium, platinum and other precious metals. The gold, silver, platinum, palladium and other precious metals value is as high as tens of thousands of dollars. According to a 2010 United Nations environment program data, e-paper waste products of the global market up to 40 million tons each year, the metal and nonmetal resources value of one hundred billion yuan. Therefore, waste electrical appliance properties have significant potential resource recycling.

Studies have proved that waste of electrical products manufacturing process has a cost advantage compared to the new system. That is to say, if the recovery is big, the recycled products which can be used, the average production cost of manufacturers is low. Wastes recycling are a long-term goal. Simple reuse was disassembled sorting out the constituent of the pure material. Iron, copper, aluminum and other metal smelt production. The CRT glass kinescope glass shell. Plastic sent to plastic products factory. The production performance is low. A lot of material in waste electrical appliances has not been effectively use. Such as polyurethane, circuit board base material, need to continue to develop new USES.

From what has been discussed above, through feasible technical means, acceptable economic cost to deal with the toxic and harmful substances, recovery available material, is an important work of waste electrical equipment resource utilization, harmless part.

\section{Status Quo at Home and Abroad}

Electronic waste at home and abroad are number of high-growth, high environmental hazards and potential resources. It is very difficult to handle. Compared with the developed countries, the disposal of waste electric and electronic products research in China started relatively late. The related basic research and technology development lag. According to the survey, at present, the city's large amount of electronic waste has three outlets. Converted into the secondary market after renovation; Easy disassembly, low utilization; Landfill with the living garbage.

Looked from the reality, the recycling and processing of waste electrical appliances in China scattered disorderly state as a whole. Waste of resources is relatively serious. Environment pollution is also more common. Although the Chinese government pay a attention on the environmental and health issues of electronic waste, it has not issued a special law. The competent administrative department introduced some scattered regulations according to the needs of management. "Clean production promotion law", "solid waste pollution environment protection law" circular economy promotion law "the three law have some of the basic law of the relevant provisions. But it is only 
principled regulations. Operability is not strong. It has brought many difficulties in law enforcement. This is bad for the recycling of electronic waste ${ }^{[1]}$. There are few regular recycling plant. Most of the plant is a small cottage recycling plant. Recycling market is disordered, consumers lack of environmental protection consciousness, relevant enterprises enthusiasm is not high. All of these lead to recycle remanufacturing business operation is quite difficult.

European countries of waste electrical and electronic product recycling system can be divided into two classes. One kind is already resolved from the national legislation level. These countries formulate special and resource utilization of solid waste pollution prevention measures and support technical regulations. These countries establish recovering waste electrical and electronic system and effective operation, such as Belgium, Denmark, the Netherlands and so on. Another kind of countries do not have formulated laws and regulations. They are based on waste management law. They established a perfect recovery system. Such as Germany, France, the UK. To a great extent, control of the waste electrical and electronic recycling may be in the process of environmental pollution and resource waste [3].

We had a high cost of recycling waste electrical and electronic. Electronic waste prefer to commodity attribute in our country [4]. In people mind, the waste electrical appliance is not garbage, but a junk, is secondhand goods. So they want to product quality. Different brands, different s and the condition of the electrical appliances will have different price. Some appliances complete loss use value. They have become the real meaning of electronic waste. Such electronic waste also can sell a few yuan to tens of dollars. This creates a high cost of recycling. Not only in China, all economic less-developed countries. People's living standard is low. People have strong demand for cheap old appliances. Such high prices higher demand provides a strong support in order to maintain the price of the old appliances recycling.

The attribute of electronic waste in the developed countries is "junk". They don't embody the value in collecting section. They do not have the property of commodity. Nullifier must pay fee if they want to discarded garbage. In this case, the cost of recycling waste electrical and electronic products is very low. Many developed countries exported the second-hand electronic appliances to eastern Europe, South America and other countries. They realize reuse of waste electrical and electronic. And they achieved good economic benefits.

In our country, the technology which conforms to the regional resource and disposal research are not deep enough. With the increase of the waste electrical and electronic products, our lag is especially prominent in researching and development of disposal equipment. In general research and form a complete set of processing equipment, enterprise is still in wait-and-see status.

Our country lack professional talents in the aspect of waste electrical and electronic recycling and processing. The management of waste electrical appliance is a complex system. It involves broad areas and wide scope. Government technology alone is not enough. Technology is very extensive, including professional training, the end of the development of the process equipment, electronic products processing, technology consultation, etc.

\section{The Suggestions and Countermeasures}

PerfectingLegislation,StrictlyEnforced.Enterprises should adhere to laws, regulations, standards a nd policies for the fundamental. Enterprises should be in accordance with the requirements for envir onmental protection fund audit standard operation. Enterprises should be guided by market access. Enterprises should improve waste electric and electronic products recycling and disposal system. Enterprise should make electronic waste comprehensive utilization technology as the main content. Companies should 
be to reduce the pollution of the environment for the purpose, constantly promote the extension of $i$ ndustry chain. In produce good social benefits and economic benefits at the same time, enterprises $\mathrm{s}$ hould strive to in the process of the development of circular economy in China have a good effect. Enterprises should strengthen environmental protection campaign and recycling efforts, continuousl y improve the disassembly process of waste electric and electronic products. Enterprises should stre ngthen the depth of the use to product, in order to achieve energy conservation and emissions reduct ion, reducing energy consumption, improve the effect of resource utilization.

Technological Innovation to Keep Pace with The Times, Focus on Harmless and High Value. Technology is the importance factor to impact the recycling and disposal of waste electrical and electronic products industry in China, including technical route selection, process optimization, the processing technology development, processing, disposal equipment research, etc. We want to solve the problem of dismantling and classification. We want to solve all kinds of the secondary pollution problem in the process of material recycling [5]. We need to study the reduction technology and wastewater zero emissions technique of the water. We are going to study new technology of the comprehensive utilization of secondary waste residue after the disposal and zero emissions technology. We are going to study secondary waste disposal technology and the technology of discharging standard..

Selection of technical route should respect the national conditions. We should absorb the successful experience of developed countries for reference. We are guided by the concept of sustainable development. We realize the process of technological innovation. We build a number of valuable engineering demonstration line or enterprise. This is the key to solve the problem of waste electric and electronic products in China.

Technical Support and Personnel Training. Waste electric and electronic products disassembly processing industry belongs to the emerging industry. Enterprises lack of professional talents, especially the electronic wastes professional talents. We should intensify development waste electrical and electronic recycling technology as well as the development of the process equipment suited to China. We should make full use of all the power of professional talents in related field. We will provide sufficient technical support for government's decisions and actions through consulting, training, project cooperation, etc.

\section{References}

[1] Jiring Cui, Eric Forssbexg, Mechanical recycling of waste electric and electronic equipment: a review [J]. Journal of Hazardous Materials. 2003 (B99): 243-263.

[2] Bo Liu. Application Research On Recovery Technology Of China Waste Electrical And Electronic Equipment [D]. Beijing: Beijing University Of Technology, 2011.

[3] Ruilin Song. The Legal System Of Electronic Waste Recycling Research In China [D]. Shijiazhuang: Shijiazhuang University of Economics, 2007.

[4] Ming Yan. The Thinking Road Of Recycling Of The Waste Electrical Appliance [J]. Renewable Resources Research, 2005 (3):19-22.

[5] Bin Chen. Status Quo of Dismantling Waste Electronic Equipment Industry in Shanghai and Its Development Trend [J]. Shanghai Environmental Sciences, 2014, 33(5):215-219. 